\title{
EDITORIAL: A complicated post-documentary era
}

S

INCE early in the first decade of this century, the concept of documentary-never beyond contestation - has entered into a state of generic uncertainty. Reflecting on these developments, John Corner, in an influential article, dubbed the current context of production as 'Post-documentary' (Corner, 2002). In his view, the documentary tradition has always encompassed a range of approaches:

1. Documentary as social commentary seeking to inform audiences as citizens rather than consumers.

2. Documentary as Investigative Reporting, once the most extensive use of documentary methods on television.

3. Documentary as Radical Interrogation and Agit-Prop as found in the practices of independent cinema.

4. Documentary as popular 'factual' entertainment driven by ratings and box office. The latter approach has become dominant in broadcasting, bringing with it new demands. Documentary programmes on broadcast television have been progressively replaced by lavish series, formulaic docu-soaps or Reality TV. In these circumstances those seeking to preserve the breadth of the documentary tradition are either abandoned or, if accepting (however reluctantly) the new situation, find their projects watered down, diverted into niche channels and controlled by programmers demanding certain strict formulas.

Another troubling implication is that post-documentary forms threaten the legitimacy and credibility of the documentary tradition as a whole. If objectivity is merely one approach to actuality then it becomes just a matter of opinion, fracturing the possibility of rational agreement. Then there is a privatising impact of the ideological focus of postdocumentary programming which, forsaking the exploration of collective issues, tends to claim that the paramount realm of social life is the subjective and personal (Palmer, 2002). Under these pressures, the civic mode of documentary, once seen as the hallmark of good documentary practice, ekes out a half-life at the margins of broadcasting with the ever-present possibility of extinction.

One potent ideological impact of popular factual television is that it threatens the key claim of documentary practice:

the demise of the 'claim on the real' that has sustained documentary to date. It has gone, over, finished with. Documentary and factual TV now exist in a space that is neither wholly fictional nor wholly factual, both yet neither. (Dovey, p. 11)

This statement, however, rather misses the point. Rather than being 'finished with', the problem of the 'real' continues to exert a greater fascination as cultural and political questions of identity, of authenticity and truth have become nodes of contestation at the individual, communal and national level. Other observers are more sanguine:

6 PACIFIC JOURNALISM REVIEW 21(1) 2015 
For all the many attempts to commodify the real through the apparently endless stream of performance-oriented reality shows, there remains a tangible public appetite for the type of cutting-edge documentary which attempts a serious engagement with real-life events and concerns. (Kilbourne, 2004, p. 31)

One symptom of this tangible appetite can be found in the rise of citizen journalism, which, however evaluated, still answers to a civic impulse. Adding to the surveillance of authorities - as in the case of racially motivated attacks by white police in Ferguson on African-Americans - this eyewitness function can supplement professional forms of reporting (Outing, 2005). On the other hand, it can become merely a form of self-promotion, as in the case of the selfie and celebrity-centric Twitter.

On the positive side, some documentary makers are welcoming the opportunities offered by digital media to significantly reduce production costs and open up new means to distribute their work online. This means that the strategy of aggregating niche audiences (rather than the one-off, usually short-term capture of a mass audience through broadcasting) has become the new channel for traditional documentary practice. After all, even in broadcasting, the engaged and attentive audience for documentaries is comparatively small.

It is worthwhile acknowledging that digital technologies have created new opportunities for niche production via new forms of fundraising, such as crowd funding and crowd investment, as well as online distribution. The key problem for many documentary makers is, however, the multiplicity of demands that such opportunities present. The documentary maker must assume the roles of PR person, salesperson, fundraiser, public speaker and distributor. Alongside necessary production-focused skills and talents, skills in networking and pitching are now required, and these become a drain on energy and stamina (Sorensen, 2012). The Act of Killing, one of the documentaries considered in what follows, took ten years to complete - in part because of political resistance but also because of the time-consuming efforts involved in putting together a loose and shifting consortium of funders.

Nor is the 'safer' broadcast route without its problems. In the New Zealand case, though this is a general phenomenon, it has been observed:

Whether or not publicly subsidized programming can deliver public service goals in the broadcast marketplace depends on the accommodation of priorities other than revenue and ratings. Continued subsidy for social documentary as a discrete genre is a key element in preserving television programme diversity for as documentary past truths and reality claims become untenable only social purpose remains to differentiate the genre from the ragbag of social programming. (Debrett, 2012, p. 20)

In the New Zealand and Asia-Pacific region, the problems of funding are particularly acute for two broad reasons. The first of these is the modest scale of local funding and its built-in criterion of telling national stories. As Peter Thompson from Victoria University 
observed in his address to the Pacific Journalism Review 20th Anniversary Conference in November 2014, New Zealand Film Commission (NZFC) funding criteria (matched by similar criteria used by New Zealand On Air (NZOA)) struggles to be inclusive under a set of criteria:

Did the funded projects a) provide pathways and careers for people, b) did they increase economic activity, c) did more people watch the funded projects d) were they culturally significant, e) and show creativity and originality?

In principle, Thompson noted that none of these criteria were undesirable, but they may not always be internally compatible and are certainly hard to define. Despite some investments in documentary productions over the years by the NZFC and NZOA's roll-out of a digital fund - discussed in Anna Jackson's article - the overall trend is to prioritise ratings and marketability. Evidence from the United States, a much wealthier funding environment, suggests that broadcast funding tends to inhibit creativity and exploration, thereby drawing documentary markets and government agencies into an approach that celebrates nationhood (Handley \& Rutigliano, 2012). Having acknowledged this, it would be unfair not to recognise that funders such as the NZOA and the NZFC have, in the past and present, provided modest support for projects with no immediate market appeal. But as Alister Barry, producer-director of a series of well-regarded documentaries, Someone Else's Country, The Hollow Men and, most recently, Hot Air, indicated:

Q. You began making this documentary in 2009. Why has it taken you so long?

\begin{abstract}
Alister Barry: The short answer is money. If you have no money then you have to substitute your own time and effort for a proper budget, doing much of the work yourself. There is also the fact that there has been no book written on this subject in New Zealand so I had to do a lot of reading and research and then write that up before condensing it into a documentary script.
\end{abstract}

Nonetheless documentary makers are placed on the horns of a dilemma: to go independent or accept prevailing political and government agendas.

All creative endeavours face constraints but there remains the possibility, through a 'poetic' approach, to enliven the most mundane narrative or at least the commonly accepted records of the 'real'. In this regard, the article by Laurence Simmons explores some of the formal methods for transvaluing a sense of inheritance and history.

Against issues of production funding, there is the pipeline problem of training aspiring documentary makers. This is limited even in the rich metropolitan centres of Australia and New Zealand, but for smaller nations throughout the region, the tendency for wealthier nations to invest in their national film and television culture, undercuts the development of local forms of cultural expression.

Such local forms of cultural expression, including but not limited to documentary making, 
are also under threat in the intensifying political and cultural conflicts of post-colonialism and neo-colonialism in the Asia-Pacific region. In Fiji, New Caledonia, Papua New Guinea and Timor-Leste, for example, political elites have sought, and still seek, to suppress popular movements for democratic change. Documentary makers, exemplified by Max Stahl's account of events in Timor-Leste or Jim Marbrook's work on Cap Bocage, have an important role as witnesses to political events virtually invisible in the mainstream media.

Finally, New Zealand and Australia (albeit in different and sometimes conflicted ways) are themselves caught up in a similar set of tensions between the logic of neo-liberalism against the maintenance, if not extension, of democracy. As Kim Webby's documentary, The Price of Peace, about the police raids on the Tūhoe people in Te Urewera, demonstrates it is not just in the 'periphery' but at the centre that civic freedom is under threat.

Caught inside the Matryoshka doll of the new geometry of power, New Zealand and Australian have their own struggle for autonomy. As weaker and more junior players in the New World Order, propelled by the global hegemony of American corporate capitalism, there is a need to address issues of national identity and sovereignty-typified by the ongoing, primarily secret, negotiations for a Trans-Pacific Partnership Agreement.

In New Zealand and the Asia Pacific region, particularly, there is a clear and present need for the practice of documentary in the tradition of civic activism. The following articles in this themed section explore the aesthetic and cultural dynamics of capturing popular struggles and how documentary makers respond in the field to rethink how to represent objectively new struggles and new contexts of real life.

\section{References}

Corner, J. (2002). Performing the real: Documentary diversions. Television and New Media 3, 255-69.

Debrett, M. (2004). Branding documentary: New Zealand's minimalist solution to cultural subsidy. Media, Culture \& Society, 26(1), 5-23.

Dovey, J. (2000). Freak show. First person media and factual television. London: Pluto Press.

Handley, R. L., \& Rutigliano, L. (2012). Journalistic field wars: Defending and attacking the national narrative in a diversifying journalistic field. Media, Culture \& Society 34(6), 744-760.

Kilborn, Richard. (2004). Framing the real: Taking stock of developments in documentary. Journal of Media Practice 5(1), 25-32.

Outing, S. (2005, May 31). The 11 Layers of citizen journalism. www.poynter.org/uncategorized/69328/the-11-layers-of-citizen-journalism/

Palmer, G. (2002, August). Big brother: an experiment in governance. Television and New Media 3(3), 295-310.

Sørensen, Inge Ejbye. (2012). Crowdsourcing and outsourcing: The impact of online funding and distribution on the documentary film industry in the UK. Media, Culture \& Society 34(6), 726-743.

Professor Barry King

Professor of Communications

Auckland University of Technology

PACIFIC JOURNALISM REVIEW 21 (1) 20159 
EARLIER versions of three unthemed articles in this edition were presented as papers during the Pacific Journalism Review 20th Anniversary conference in November 2014. They continue from Volume 1 of PJR 20 Years on 'Political Journalism in the Asia-Pacific' (Robie, King, Cass \& Bacon, 2015). In the first article, Chris Thomson, Dawn Bennett, Michelle Johnston and Bonita Mason urge collaborations so that journalists can transform the way they conceptualise their careers and help secure a 'sense of place' for Indigenous people in the media. Assessing a project involving student journalists with Noongar community organisations in Western Australia, they make a compelling argument for re-emphasing the 'where?' question in journalistic investigation in response to globalisation.

Lyn Barnes and Elesha Edmonds analyse changing death coverage in The New Zealand Herald over a 40-year period in their article entitled 'If it bleeds, it leads?'. Selecting three sample periods in 1973, 1993 (when the newspaper was a broadsheet) and 2013 (after becoming a 'compact' publication), the authors examine the 'increased visibility of death stories' and the reasons for it.

The rapid advances with social media can be used by academics to develop and retain links with their students and alumni and two early adopters of Facebook and Twitter in Australia for communication with students argue strongly in favour of social networking. Nasya Nahfen and Alex Wake, whose industry and research expertise is in the AsiaPacific region, have researched 'tweeting, friending and reporting' over a five-year time frame and also draw from their experience as media educators.

Professor David Robie

Managing Editor

Pacific Journalism Review

www.pjreview.info

Reference

Robie, D., King., B., Cass., and Bacon, W. (2015). Political Journalism in the Asia-Pacific. Auckland: Pacific Media Centre and Pacific Journalism Review. 